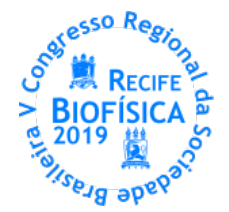

\title{
FUNÇÃO DA ÁGUA COMO TAMPÃO TÉRMICO PARA OS SERES VIVOS
}

\author{
Soraya Nunes Barbosa ${ }^{1 *}$, Isabela Nunes Barbosa Santos ${ }^{2}$, Maísa de Sousa dos Santos ${ }^{3}$; Rita de Cássia Meneses \\ Oliveira ${ }^{4}$, Aldeídia Pereira de Oliveira ${ }^{4}$, Maria do Carmo de Carvalho e Martins ${ }^{4}$; Paulo Humberto Moreira Nunes ${ }^{4}$, \\ ${ }^{1}$ Curso de Graduação em Medicina Veterinária/Monitora de Biofísica; ${ }^{2}$ Curso de Graduação em Farmácia, ${ }^{3}$ Curso de Mestrado em Ciências \\ Farmacêuticas; ${ }^{4}$ Departamento de Biofísica e Fisiologia. Universidade Federal do Piauí. \\ *sorayanb1@gmail.com
}

\begin{abstract}
INTRODUÇÃO
Os seres vivos estão continuamente expostos a variações de temperatura, tanto por conta da produção interna de energia, decorrente do metabolismo celular, quanto pela absorção ou perda de calor decorrente das trocas energéticas com o meio ambiente. Tratando-se particularmente de animais homeotérmicos, é importante que essas variações de temperatura não sejam muito elevadas, ou, em outras palavras, que sejam amortecidas, a fim de evitar dispêndio exagerado de energia para promover o aquecimento corporal, ou estratégias arriscadas, ou até mesmo fatais (como uma dilatação exagerada dos vasos sanguíneos da pele), com o intuito de possibilitar o resfriamento do organismo. Este trabalho apresenta um roteiro de prática de Biofísica com o objetivo de simular a função da água como um tampão térmico, ou seja, como um amortecedor de variações de temperatura; circunstância altamente adequada para o controle da temperatura corporal dos seres vivos. Esse comportamento termodinâmico da água é decorrente do seu elevado calor específico, quando comparado com o de outras substâncias orgânicas no estado líquido como, por exemplo, o etanol ou o óleo de soja. O calor específico (c) de uma substância é definido termodinamicamente como a quantidade de calor (Q) necessária para alterar de $1^{\circ} \mathrm{C}(\Delta \theta)$ a temperatura de $1 \mathrm{~g}$ de massa $(\mathrm{m})$ dessa substância $(c=Q / m \cdot \Delta \theta)$. Uma substância com elevado calor específico pode receber ou perder razoáveis quantidades de calor sem sofrer grandes variações de temperatura. Essa propriedade física é altamente desejável para um componente molecular dos seres vivos, pois os mesmos, para manter-se em atividade, precisam continuamente gerar energia através do metabolismo celular de substâncias energéticas, como a glicose, liberando, inevitavelmente, calor. Se essa energia calorífica não for imediatamente retirada do interior de, por exemplo, uma célula, a temperatura da mesma sofreria uma brusca elevação que seria seguida de uma brusca diminuição, logo que o excesso de calor fosse retirado. E essa variação de temperatura seria tanto mais exagerada quanto menor fosse o calor específico médio dos componentes dessa célula. Caso essa célula contenha com uma elevada proporção de água, as variações de temperatura seriam bem menores, ou seja, seriam amortecidas. Não por acaso, a água é o principal componente molecular dos seres vivos. A estratégia da aula prática é evidenciar a importância biológica dessa propriedade física da água simulando o comportamento térmico de três "células" artificiais compostas de três líquidos de diferentes calores específicos: água $\left(1 \mathrm{cal} / \mathrm{g} .{ }^{\circ} \mathrm{C}\right)$, etanol $\left(0,59 \mathrm{cal} / \mathrm{g} .{ }^{\circ} \mathrm{C}\right)$ e óleo de soja comercial (desconhecido). Para isso, massas iguais $\left(m_{1}\right)$ de cada líquido com calor específico $\left(c_{1}\right)$ são colocadas em recipientes "adiabáticos", e a temperatura de cada "célula" é medida até que entre em equilíbrio térmico com o ambiente $\left(\mathrm{T}_{1}\right)$. A seguir, cada "célula" recebe uma determinada
\end{abstract}

quantidade de calor $(\mathrm{Q})$ por meio da introdução, em cada uma, de frascos de vidro com dimensões, forma e espessura semelhantes contendo uma massa de água $\left(\mathrm{m}_{2}\right)$ aquecida a uma temperatura mais elevada que a do ambiente $\left(T_{2}\right)$. A partir desse instante, a temperatura de cada "célula" é medida a intervalos regulares até que se estabeleça o equilíbrio térmico no interior das mesmas (Esquema I) e a temperatura do sistema atinja o valor de equilíbrio $\left(T_{E q}\right)$. Os resultados devem mostrar que a variação de temperatura será menor na "célula" composta de água do que nas outras. Colocando-se os dados em um diagrama temperatura versus tempo, espera-se perceber visualmente o comportamento físico vantajoso da água em comparação com o comportamento dos outros líquidos testados, evidenciando-se a sua função como tampão térmico.

\section{MATERIAIS E MÉTODOS}

Materiais: Banho-maria; 3 recipientes "adiabáticos" (caixas de isopor com tampa, marcadas com "A", "E" ou "O"); 3 termômetros; água destilada $(2,5 \mathrm{~kg})$; etanol absoluto $(1 \mathrm{~kg})$; óleo de soja comercial (1 kg); 3 frascos de vidro com tampa (capacidade de 600 $\mathrm{ml}$, com as mesmas dimensões e características).

Método (Procedimento): 1-Colocar na caixa "A" $1 \mathrm{~kg}$ de água destilada; na caixa "E" $1 \mathrm{~kg}$ de etanol absoluto e na caixa "O" $1 \mathrm{~kg}$ de óleo de soja; 2-Mergulhar o bulbo de um termômetro no líquido de cada caixa, em posições, locais e alturas semelhantes, e medir a temperatura das "células" até que os sistemas entrem em equilíbrio térmico com o ambiente, tampando as caixas em seguida; 3-Colocar $500 \mathrm{~g}$ de água destilada em cada frasco de vidro e aquecê-los a $70^{\circ} \mathrm{C}$ (Atenção: Não trabalhar com temperatura superior ao ponto de ebulição do etanol!); 4-Tampar os frascos e colocar um em cada "célula", em posições idênticas; 4-Marcar o tempo e medir a temperatura de cada "célula" em intervalos de 1 ou 2 minuto até que o sistema atinja um equilíbrio; 5-Distribuir os resultados em um diagrama com a temperatura no eixo das ordenadas e o tempo no eixo das abscissas, usando símbolos diferentes para cada líquido (Pode ser usado um programa computacional, como o GraphPad Prism, por exemplo).

O valor teórico da temperatura de equilíbrio de cada "célula" pode ser calculado pela equação abaixo (Eq. I), que leva em conta também a influência do calor liberado pela massa $\left(\mathrm{m}_{3}\right)$ do vidro, de calor específico $c_{3}\left(0,16 \mathrm{cal} / \mathrm{g} .{ }^{\circ} \mathrm{C}\right)$, que contém a água aquecida à temperatura $\mathrm{T}_{2}$.

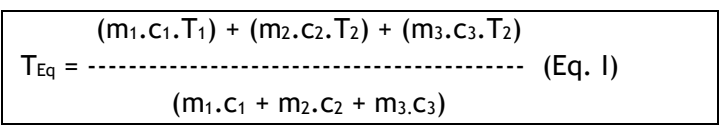


Equação I. Cálculo da temperatura de equilíbrio de cada sistema, conhecendo-se a massa $\left(m_{1}\right)$, o calor específico $\left(c_{1}\right)$ e a temperatura inicial $\left(T_{1}\right)$ de cada "célula" (composta de água, etanol ou de óleo de soja); a massa $\left(\mathrm{m}_{2}\right)$, o calor específico $\left(\mathrm{c}_{2}\right)$ e a temperatura inicial $\left(T_{2}\right)$ da água e a massa $\left(m_{3}\right)$, o calor específico $\left(c_{3}\right)$ e a temperatura inicial $\left(T_{2}\right)$ do frasco no qual a água aquecida foi colocada.

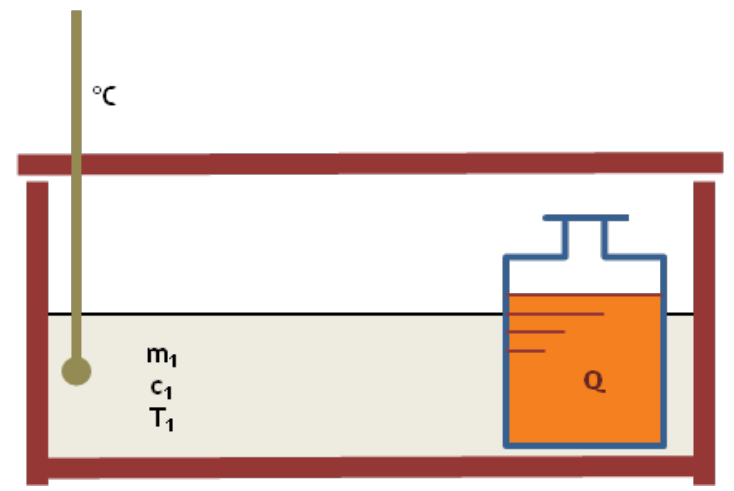

Esquema I. Montagem do sistema para medir e acompanhar a alteração da temperatura inicial $\left(T_{1}\right)$ de uma massa $\left(m_{1}\right)$ de um líquido com calor específico $\left(c_{1}\right)$ quando a mesma recebe uma quantidade de calor $(\mathrm{Q})$, fornecida por um frasco de vidro de massa $\mathrm{m}_{3}$ e calor específico $c_{3}$ contendo uma massa de água $\left(\mathrm{m}_{2}\right)$, de calor específico $\left(\mathrm{c}_{2}\right)$, ambos aquecidos a uma temperatura $\left(T_{2}\right)$.

\section{RESULTADOS E DISCUSSÃO}

Em cada sistema a temperatura do líquido se eleva progressivamente até atingir valores de equilíbrio. Entretanto, as temperaturas de equilíbrio térmico não são iguais, sendo a do sistema que contém água a mais baixa de todas (Tabela 1).

Tabela 1. Registro das temperaturas de massas $(1 \mathrm{~kg})$ de água, de etanol e de óleo de soja comercial após receberem uma quantidade fixa de calor $(36,9 \mathrm{kcal})$ em função do tempo. (Fonte: Laboratório de Biofísica/UFPI).

\begin{tabular}{cccc}
\hline \multirow{2}{*}{ Tempo (min) } & \multicolumn{3}{c}{ Temperatura $\left({ }^{\circ} \mathrm{C}\right)$} \\
\cline { 2 - 4 } & Água & Etanol & Óleo de soja \\
\hline 0 & 25,3 & 25,6 & 25,2 \\
1 & 25,6 & 25,8 & 25,3 \\
2 & 27,1 & 26,3 & 25,5 \\
3 & 28,7 & 28,5 & 26,2 \\
4 & 30,9 & 30,7 & 27,6 \\
5 & 32,3 & 33,3 & 29,6 \\
6 & 32,9 & 34,8 & 31,2 \\
7 & 33,8 & 35,9 & 33,4 \\
8 & 34,1 & 37,2 & 34,5 \\
9 & 34,3 & 38,1 & 35,9 \\
10 & 35,0 & 38,8 & 37,3 \\
11 & 35,1 & 39,4 & 38,1 \\
12 & 35,8 & 39,6 & 38,9 \\
13 & 35,7 & 39,8 & 39,6 \\
14 & 36,3 & 40,4 & 40,3 \\
15 & 36,0 & 40,3 & 40,5 \\
16 & 36,3 & 40,2 & 40,7 \\
17 & 36,4 & 40,5 & 41,4 \\
18 & 36,4 & 40,8 & 42,3 \\
19 & 36,2 & 40,5 & 42,4 \\
20 & 36,3 & 40,7 & 42,5 \\
21 & 36,4 & 40,8 & 42,9 \\
22 & 36,4 & 40,8 & 42,8 \\
23 & 36,5 & 40,9 & 43,2 \\
24 & 36,5 & 40,9 & 43,3 \\
25 & 36,5 & 40,8 & 43,3 \\
\hline Equilíbrio & 37,4 & 42,2 & 44,3 \\
& & &
\end{tabular}

Os valores verificados das temperaturas de equilíbrio de cada sistema mostraram-se próximos, mas inferiores em relação aos valores calculados pela Equação I. Provavelmente essas diferenças se devam ao tempo de observação e ao fato de que os sistemas utilizados podem não ter se comportado de modo perfeitamente adiabático.

Quando expressos como variações temporais da temperatura de cada "célula" em relação às suas respectivas temperaturas iniciais, os resultados obtidos mostram nitidamente que, para uma mesma quantidade absorvida de calor, a variação de temperatura da água é significativamente menor que a do etanol, e mais ainda, que a do óleo de soja comercial (Figura 1), indicando que o calor específico do óleo deve ter um valor menor que o do etanol. Pode ser observado também que o tempo necessário para que o equilíbrio térmico seja atingido é praticamente igual para a água e para o etanol e bem maior para o óleo de soja comercial, indicando que a velocidade de condução do calor deve ser menor neste do que na água ou no etanol.

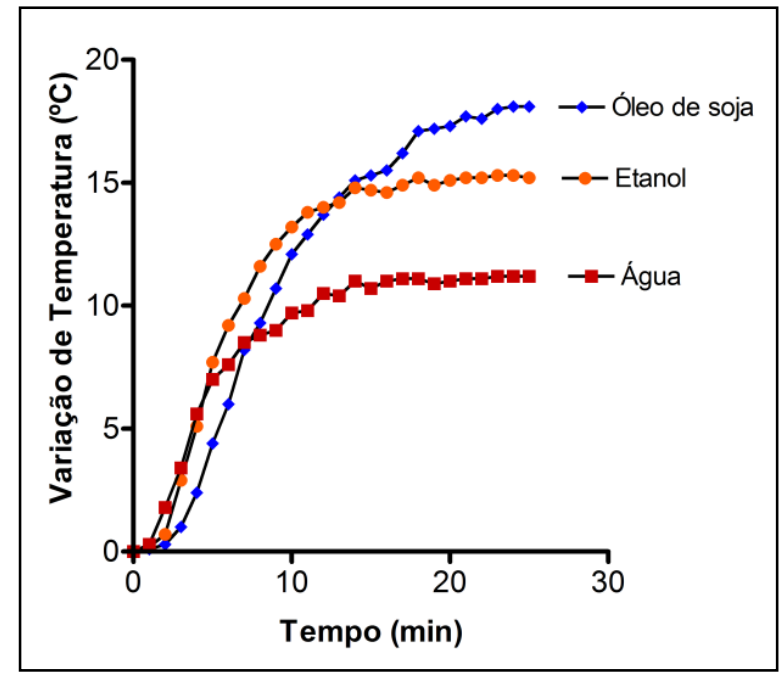

Figura 1. Variações das temperaturas de massas iguais $(1 \mathrm{~kg})$ de água, de etanol ou de óleo de soja comercial, após receberem uma quantidade fixa de calor $(36,9 \mathrm{kcal})$ em função do tempo. (Fonte: Laboratório de Biofísica/UFPI).

\section{CONCLUSÕES}

Os resultados mostram claramente que, para uma mesma quantidade de calor recebida, massas iguais de água, etanol e óleo de soja comercial sofrem diferentes variações de temperatura, sendo a da água a menor de todas. A realização da aula prática proposta, portanto, permite, por comparação com o comportamento térmico de outros líquidos, evidenciar o papel da água como um tampão térmico que possibilita o amortecimento de variações de temperatura ao receber (ou perder) uma determinada quantidade de calor. Por consequência, permite aos alunos perceberem que a presença de uma elevada proporção de água na composição dos seres vivos confere aos mesmos a capacidade de evitar grandes variações de temperatura provocadas pela inevitável produção de calor decorrente da atividade metabólica, essencial para a sobrevivência das células. Ademais, permite concluir que uma desidratação severa torna um organismo vivo mais susceptível de sofrer variações acentuadas da temperatura corporal, especialmente na vigência simultânea de processos que incrementem o metabolismo celular, ou na presença de variações acentuadas da temperatura ambiente. 